ORIGINAL ARTICLE

\title{
Major differences in prevalence of overweight according to nationality in preschool children living in Germany: determinants and public health implications
}

\author{
J Kuepper-Nybelen, A Lamerz, N Bruning, J Hebebrand, B Herpertz-Dahlmann, H Brenner
}

Arch Dis Child 2005;90:359-363. doi: 10.1136/adc.2004.052423

See end of article for authors' affiliations

Correspondence to

Dr H Brenner, Department of Epidemiology, German Centre for Research on Ageing, Bergheimer Str 20, 69115 Heidelberg, Germany; brenner@dzfa. uni-heidelberg.de

Accepted 15 October 2004

\begin{abstract}
Aims: To investigate the prevalence of overweight according to nationality in preschool children living in Germany, and to establish the determinants responsible for differences in body mass index.

Methods: The study was performed within the context of the 2001/2002 obligatory health examination before school entry in the city of Aachen, Germany. Of 2020 eligible children 1979 children were recruited (participation rate: 98\%). Children's height and weight were measured using a standardised protocol. The parents completed a standardised questionnaire on sociodemographic factors and possible determinants of nutritional status. Being overweight was defined according to age and sex specific reference values for German children as well as according to international reference values.

Results: The study population included 452 (22.9\%) children with other than German nationality. Among these children the prevalence of overweight was twice as high than among German children $114.8 \% \mathrm{v}$ 7.2\%). Prevalence of most known risk factors for overweight, such as low physical activity, high consumption of soft drinks, and frequent visits to fast-food restaurants was higher in the children with other nationalities than in the German children. Multivariate analyses revealed that most of the difference in prevalence of obesity by nationality is explained by known risk factors of overweight, especially education of mother and watching TV.

Conclusions: The apparent ethnic differences could be explained by two non-ethnic but socioeconomic factors. In preventing overweight in children, there is the need to identify and deal with high risk environments rather than high risk ethnic groups.
\end{abstract}

O besity is considered to be the most prevalent nutritional disease in developed countries, and it is widely acknowledged that obesity has emerged as an epidemic. ${ }^{1}$ The incidence and prevalence of obesity in children and adolescents are increasing in many countries around the world ${ }^{2}$ including countries in Europe. ${ }^{3}$ German preschool children have gained a higher body mass index (BMI) during the last 30 years according to a recent study conducted in the city of Aachen, which also revealed that increasing BMI affected children in the upper weight range more than those in the lower range. ${ }^{4}$ It is known that obesity in children persists into adulthood ${ }^{5}{ }^{6}$ and increases the risk of obesity related morbidity later in life. ${ }^{78}$

Regarding obesity, there seems to be great variation by ethnic groups both between and within populations. In the United States, where obesity is particularly common, a large variation in childhood obesity by ethnic groups has been shown, ${ }^{9}$ with rates generally highest for Hispanic and NativeAmerican children and for African-American girls. ${ }^{10}$ Estimates of the prevalence of overweight of children in European countries suggest that prevalence is higher among the southern countries of Europe. ${ }^{11}$ However, pertinent data comparing prevalences of overweight according to ethnic groups within European countries, including Germany, are scarce.

Several factors have been discussed that may be contributing to different obesity prevalence rates in ethnic groups. They include environmental factors such as high caloric food supply and a rapid change from an active to a sedentary lifestyle and socioeconomic factors. The role of the latter appears to vary across countries with different development levels. In developing countries children with higher socioeconomic status are more likely to be obese, whereas in developed countries socioeconomic status is inversely related to obesity. ${ }^{12}$ Other contributing factors are race, which remains an independent risk factor after controlling for differences in socioeconomic status, ${ }^{13}$ physical activity levels which vary by ethnicity, ${ }^{14}$ dietary patterns, ${ }^{15}$ and factors related to the home environment such as television watching during meals. ${ }^{16}$

Within the last decade, many European countries have faced high rates of immigration, particularly of young families, and there is now a large diversity of national groups among children living in many European countries. Recent epidemiological studies on childhood obesity in Europe have not included comparisons between children of different nationalities living in the same country. However, with regard to adequate and effective prevention programmes it is necessary to identify the risk factors and to adapt measures as much as possible. The aim of this study was to investigate the prevalence of overweight of German children and children of other nationalities living in Germany, and to establish the determinants responsible for possible differences in BMI.

\section{METHODS}

\section{Study design and study population}

All children born between 1 July 1995 and 30 June 1996, who attended the 2001/2002 obligatory health examination before school entry in the city of Aachen, Germany, and who were accompanied by a parent with sufficient knowledge of German, were enrolled in this cross-sectional study. The study was conducted in cooperation with the Aachen Public Health Service between December 2001 and July 2002 after approval by the Ethics Board of the University of Aachen. 


\section{Data collection}

The children's anthropometric data, including height and weight, were measured according to a standardised protocol as part of the routine examination conducted at the prospective primary school of the children. Body weight in underwear was measured to the nearest $0.1 \mathrm{~kg}$ and height to the nearest $1 \mathrm{~cm}$ using a digital scale (Seca column scale 910 with telescopic measuring rod, Hamburg, Germany). Body mass index (BMI) was calculated as weight $(\mathrm{kg}) / \mathrm{height}\left(\mathrm{m}^{2}\right)$. The age and sex specific BMI percentile ranks were calculated by a German internet based reference program (www. mybmi.de), which is based on pooled data from 17 epidemiological studies in Germany, including anthropometric data of 17147 boys and 17275 girls in the age range 0-18 years. ${ }^{17} \mathrm{~A}$ BMI $\geqslant$ the 90th centile was defined as being overweight. Additionally, prevalence of overweight was estimated according to the age and sex specific cut-off points derived from international data as recommended by the Childhood Obesity Working Group of the International Obesity Task Force. ${ }^{18}$ These cut-off points (boys: 17.5, 17.6, 17.7 , and $17.9 \mathrm{~kg} / \mathrm{m}^{2}$; girls: $17.2,17.3,17.5$, and $17.8 \mathrm{~kg} / \mathrm{m}^{2}$ for ages $<5.75$ years, 5.75 to $<6.25$ years, 6.25 to $<6.75$ years, and $\geqslant 6.75$ years, respectively) are linked to the widely accepted cut-off point for overweight of a BMI $\geqslant 25 \mathrm{~kg} / \mathrm{m}^{2}$.

During the examination the parents were asked to complete a standardised 42 item questionnaire, which included questions on sociodemographic factors as well as on several suggested determinants of nutritional status. The screening questionnaire was presented in German; however, one of our research assistants was always available at the survey location and was able to explain unclear items to the parents.

\section{Statistical analysis}

We first described the study participants with respect to basic sociodemographic factors. The children were categorised in German children and children with other nationalities according to the nationality of their mothers in order to take the cultural background of the mother into account, who is the person with the closest contact to the child in most cases. The nationality of the mother was strongly linked to the country where the mother has predominantly lived before age 18: more than $90 \%$ of German mothers, but less than $20 \%$ of mothers with other nationality had predominantly grown up in Germany. Hence, although no clear definition of ethnicity of the children (which is rather difficult for

Table 1 Sociodemographic characteristics of the study population $(n=1974)$

\begin{tabular}{lrr}
\hline Characteristics & $\mathbf{n}$ & $\%$ \\
\hline Gender & 1008 & 51.1 \\
$\quad$ Boys & 966 & 48.9 \\
Girls & & \\
Age & 417 & 21.1 \\
5 years & 1557 & 78.9 \\
$\quad$ years & & \\
Nationality & 1522 & 77.1 \\
German & 452 & 22.9 \\
Other & 146 & 32.3 \\
$\quad$ Turkish & 33 & 7.3 \\
$\quad$ Southern Europe & 33 & 7.3 \\
$\quad$ Central Europe & 91.9 \\
$\quad$ Eastern Europe & 99 & 21.9 \\
$\quad$ Other countries & 141 & 31.2 \\
\hline
\end{tabular}

*Southern Europe = Greece, Italy, Portugal, Spain. †Central Europe=Austria, Belgium, Denmark, France, Great Britain, Netherlands, Switzerland.

†Eastern Europe = Albania, Bosnia-Herzegovina, Bulgaria, Croatia, Hungary, Kosowo, Macedonia, Moldavia, Poland, Romania, Russia, Serbia, Ukraine, Yugoslavia.
European countries) was available in this study, nationality as defined here should closely reflect the ethnic background in most cases. Next, the prevalence of overweight as well as eating habits and various suggested risk factors for overweight were described according to nationality.

Furthermore, we used multiple logistic regression analyses to assess to what extent differences in prevalence of overweight (dependent variable) by nationality are explained by the following known or suggested risk factors or protective factors: mother's and father's school education classified according to the German school system $(<9$ years, 9 years, $10-12$ years, 13 years), watching TV on weekdays ( $<2$ hours/ day, $\geqslant 2$ hours/day), watching TV on weekends $(<2$ hours/ day, $\geqslant 2$ hours/day), doing sports or playing outside $(\leqslant 1 \times /$ week, $>1 \times /$ week $)$, consumption of sweets $(\leqslant 1 \times /$ week, $>1 \times 1$ week), consumption of savoury snacks $(\leqslant 1 \times /$ week, $>1 \times 1$ week), consumption of soft drinks $(\leqslant 1 \times /$ week, $>1 \times /$ week $)$, visiting fast-food restaurants $(\leqslant 1 \times /$ week, $>1 \times /$ week $)$, BMI of mother $\left(<25 \mathrm{~kg} / \mathrm{m}^{2}, \geqslant 25-<30 \mathrm{~kg} / \mathrm{m}^{2}, \geqslant 30 \mathrm{~kg} / \mathrm{m}^{2}\right)$, and BMI of father $\left(<25 \mathrm{~kg} / \mathrm{m}^{2}, \geqslant 25-<30 \mathrm{~kg} / \mathrm{m}^{2}, \geqslant 30 \mathrm{~kg} / \mathrm{m}^{2}\right)$. These variables were added one by one to the regression model, and changes in odds ratios (ORs) for nationality by inclusion of these covariates were recorded. The covariates were entered into the model in the order of their impact on the OR-that is, the variable which changed the OR for nationality the most was entered first, and this algorithm was repeated until none of the remaining covariates changed the OR by more than $5 \%$. Finally, a fully adjusted model was calculated in which all mentioned risk factors were considered. All analyses were carried out with the SAS statistical software package version 8.2.

\section{RESULTS}

Of the 2020 children who fulfilled the inclusion criteria, 1979 parents $(98.0 \%)$ agreed to participate in the study. Overall, a sample of 1974 children remained for the final analysis after exclusion of one child without determination of anthropometric measures and another four children without information on the nationality of the mother.

Table 1 gives basic characteristics of the study population. About half of the children were boys, and the majority were 6 years of age $(78.9 \%)$. About one quarter of the children had a nationality other than German. Most of them were Turkish children $(32.3 \%)$ or came from Eastern European countries $(21.9 \%)$.

Table 2 presents the prevalence of overweight in German and non-German children according to German and international reference values. Based on the German values, a $\mathrm{BMI} \geqslant 90$ th centile was seen in $7.2 \%$ of the German children, but prevalence was more than twice as high (14.8\%) in the children with other nationality $(\mathrm{p}<0.0001)$. There were no differences in the prevalence of overweight due to sex, neither among the German $(\mathrm{p}=0.85)$ nor among the nonGerman children $(p=0.49)$. Dividing the other children by regions of origin, children from Turkey had the highest prevalence of overweight $(21.2 \%)$. In children from Southern Europe, combining the countries Italy, Greece, Spain, and Portugal, overweight was prevalent in $18.2 \%$ of the preschoolers. Prevalences of overweight were generally higher according to the international reference values, but variation of overweight between nationalities was very similar for both classification schemes. Therefore, further analyses regarding variation of overweight by nationality were carried out using the German reference values only.

Table 3 shows the prevalence of several factors known or suggested to be associated with overweight. Children with other nationality had less exercise and watched TV more often than German children; $31.9 \%$ of parents of nonGerman children compared to $8.6 \%$ of parents of German 
Table 2 Prevalence of overweight in German children and children with other nationality defined by German and international cut-off points for overweight

\begin{tabular}{|c|c|c|c|c|c|}
\hline \multirow[b]{2}{*}{ Gender } & \multirow[b]{2}{*}{ Nationality } & \multicolumn{2}{|c|}{$\begin{array}{l}\text { German reference } \\
\text { values* }\end{array}$} & \multicolumn{2}{|c|}{$\begin{array}{l}\text { International reference } \\
\text { valuest }\end{array}$} \\
\hline & & $\mathbf{n}$ & $\%$ & $\mathbf{n}$ & $\%$ \\
\hline \multirow[t]{2}{*}{ Boys } & German children & 56 & 50.9 & 69 & 42.6 \\
\hline & Children with other nationality & 30 & 44.8 & 33 & 37.9 \\
\hline \multirow[t]{2}{*}{ Girls } & German children & 54 & 49.1 & 93 & 57.4 \\
\hline & Children with other nationality & 37 & 55.2 & 54 & 62.1 \\
\hline \multirow[t]{7}{*}{ Both } & German children & 110 & 7.2 & 162 & 10.6 \\
\hline & Children with other nationality & 67 & 14.8 & 87 & 19.3 \\
\hline & Turkish children & 31 & 21.2 & 38 & 26.0 \\
\hline & Children from Southern Europe & 6 & 18.2 & 9 & 27.3 \\
\hline & Children from Central Europe & 0 & 0.0 & 2 & 6.1 \\
\hline & Children from Eastern Europe & 11 & 11.1 & 15 & 15.2 \\
\hline & Children from other countries & 19 & 13.5 & 23 & 16.3 \\
\hline
\end{tabular}

${ }^{*}$ Cut-off point for overweight: $\mathrm{BMI} \geqslant 90$ th centile.

†Cut-off point for overweight: defined to pass through BMl of $25 \mathrm{~kg} / \mathrm{m}^{2}$ at the age of 18 .

children reported their children watching TV for two hours and more on weekdays. Also consumption of unhealthy food like savoury snacks, soft drinks, and fast-food more often than once a week was more prevalent in children of nonGerman nationality. Furthermore, parents of non-German children were more often overweight themselves and were less educated than parents of German children.

Table 4 presents the analysis regarding the contribution of suggested risk factors to the differences in prevalence of overweight by nationality. In crude analysis children with nationality other than German had a 2.23-fold odds to be overweight compared to children of German nationality. This association could mostly be explained by education of the mother and by watching TV on weekdays. The OR for nationality was reduced to 1.37 after inclusion of these two covariates in the logistic regression model. The additional consideration of other risk factors did not change the OR substantially. After simultaneous inclusion of all considered risk factors in the multivariate analysis, there remained a moderate, statistically non-significant independent association of nationality with overweight (OR 1.30, 95\% CI 0.87 to 1.93). Additionally the same analysis was done dividing

Table 3 Prevalence of risk factors for overweight by nationality among preschool children living in Germany

\begin{tabular}{|c|c|c|c|c|c|}
\hline \multirow[b]{3}{*}{ Risk factors } & \multicolumn{4}{|c|}{ Nationality } & \multirow[b]{3}{*}{ p value ${ }^{*}$} \\
\hline & \multicolumn{2}{|c|}{ German ( $n=1522)$} & \multicolumn{2}{|c|}{ Other $(n=452)$} & \\
\hline & $n$ & $\%$ & $n$ & $\%$ & \\
\hline Doing sports or playing outside & 88 & 5.8 & 76 & 16.9 & $<0.0001$ \\
\hline $\begin{array}{l}\text { Watching TV on weekdays } \\
\geqslant 2 \text { hours/day }\end{array}$ & 130 & 8.6 & 143 & 31.9 & $<0.0001$ \\
\hline $\begin{array}{l}\text { Watching TV on weekends } \\
\geqslant 2 \text { hours/day }\end{array}$ & 288 & 19.0 & 212 & 47.2 & $<0.0001$ \\
\hline $\begin{array}{l}\text { Consumption of sweets } \\
>1 \times / \text { week }\end{array}$ & 1364 & 90.1 & 368 & 82.0 & $<0.0001$ \\
\hline $\begin{array}{l}\text { Consumption of savoury snacks } \\
>1 \times / \text { week }\end{array}$ & 390 & 26.0 & 220 & 49.8 & $<0.0001$ \\
\hline $\begin{array}{l}\text { Consumption of soft drinks } \\
>1 \times / \text { week }\end{array}$ & 344 & 22.7 & 190 & 42.4 & $<0.0001$ \\
\hline $\begin{array}{l}\text { Visit to fast-food restaurants } \\
>1 \times / \text { week }\end{array}$ & 70 & 4.6 & 61 & 13.6 & $<0.0001$ \\
\hline \multicolumn{6}{|l|}{ BMl of mother } \\
\hline$<25 \mathrm{~kg} / \mathrm{m}^{2}$ & 1090 & 75.0 & 257 & 62.4 & $<0.0001$ \\
\hline$\geqslant 25-<30 \mathrm{~kg} / \mathrm{m}^{2}$ & 251 & 17.2 & 115 & 27.9 & \\
\hline$\geqslant 30 \mathrm{~kg} / \mathrm{m}^{2}$ & 113 & 7.8 & 40 & 9.7 & \\
\hline \multicolumn{6}{|l|}{ BMI of father } \\
\hline$<25 \mathrm{~kg} / \mathrm{m}^{2}$ & 693 & 54.5 & 164 & 42.5 & 0.0002 \\
\hline$\geqslant 25-<30 \mathrm{~kg} / \mathrm{m}^{2}$ & 479 & 37.6 & 173 & 44.8 & \\
\hline$\geqslant 30 \mathrm{~kg} / \mathrm{m}^{2}$ & 100 & 7.9 & 49 & 12.7 & \\
\hline \multicolumn{6}{|l|}{ Education of mother } \\
\hline$<9$ years & 35 & 2.3 & 92 & 20.8 & $<0.0001$ \\
\hline 9 years & 309 & 20.4 & 133 & 30.0 & \\
\hline $10-12$ years & 423 & 27.9 & 103 & 23.3 & \\
\hline 13 years & 748 & 49.4 & 115 & 26.0 & \\
\hline \multicolumn{6}{|l|}{ Education of father } \\
\hline$<9$ years & 33 & 2.3 & 63 & 14.8 & $<0.0001$ \\
\hline 9 years & 343 & 23.5 & 121 & 28.4 & \\
\hline $10-12$ years & 284 & 19.5 & 89 & 20.9 & \\
\hline 13 years & 797 & 54.7 & 153 & 35.9 & \\
\hline
\end{tabular}


children with other nationality into subgroups (data not shown). For the Turkish children the crude odds to be overweight was 3.46 (95\% CI 2.23 to 5.38); however, this association was again strongly reduced and no longer statistically significant after full adjustment (OR 1.66, 95\% CI 0.97 to 2.83 ).

\section{DISCUSSION}

Our analyses of the prevalence of overweight by nationality among 1974 preschool children attending the 2001/2002 obligatory health examination before school entry in the city of Aachen, Germany, indicated a higher prevalence of known risk factors for obesity and a two times higher prevalence of overweight in children with other than German nationality than in German children. In Turkish children, the largest group of foreign children, the prevalence of overweight was three times higher than in German children. Multivariate analyses revealed that most of the difference in prevalence of obesity by nationality is explained by known risk factors of overweight, especially education of mother and watching TV, whereas there remained only a moderate, statistically nonsignificant association of nationality with overweight after control for these risk factors.

The proportion of people with other than German nationality living in Germany in 2001 was $8.9 \%$. However, the proportion of children with other than German nationality was higher (children 0-5 years of age: 9.7\%; children $6-14$ years of age: $10.5 \%),{ }^{19}$ and there is substantial regional variation with a much higher proportion of foreign children in the Western part than in the Eastern part of Germany. In this study $22.9 \%$ of the subjects were children with other than German nationality. Most of them held Turkish nationality (32.3\%) or came from Eastern European countries $(21.9 \%)$. This distribution is in accordance to corresponding national figures. ${ }^{19}$ Furthermore, the city of Aachen is a typical German city with respect to the population's age distribution and indicators of socioeconomic status, such as unemployment rates and the proportion of inhabitants receiving welfare payments. ${ }^{20}$ Particular strengths of this study were the very large number of participating children and the very high participation rate, making selection bias very unlikely.

Our findings of significant differences in prevalence of overweight between different ethnic groups within a country are consistent with those of US studies, generally considering ethnic groups. ${ }^{9} 102122$ Only a few European studies on BMI in children examined different ethnic groups within a country. Based on data from 1983, Caucasian and Afro-Caribbean children in Britain were found to have a similar weight-forheight index, but it was higher than that for Asian children in younger age groups. ${ }^{23}$ These patterns have been confirmed in later investigations from $1993^{24}$ and 1999. ${ }^{25}$ In France, children with Maghrebian origin were found to have a higher prevalence of obesity. ${ }^{26}$ Brussaard and colleagues, ${ }^{27}$ who investigated migrants in the Netherlands, figured out a higher risk of overweight for Turkish and Moroccan children aged 4-15 years than for Dutch children, based on data from $1992 / 1993$. In a recent study from Germany the frequency of overweight in non-German boys was 1.9 times higher and in non-German girls 1.5 times higher than in German boys and girls, respectively. ${ }^{28}$ However, none of these studies established determinants responsible for the prevalence differences.

In our investigation education of the mother emerged to be the factor contributing most to the different prevalence of overweight between German and other children. In particular, the proportion of mothers with very low levels of school education was much higher among children with a nationality other than German than among German children. Low maternal education may be associated with an insufficient knowledge of the risk factors for obesity like an unhealthy diet with a high energy intake from fat and from sugar sweetened soft drinks and a sedentary lifestyle. Low education also often goes along with low socioeconomic status. An inverse relation between socioeconomic status of the parents and obesity in children has been reported in studies from developed countries. ${ }^{29}{ }^{30}$ In the study of the migrants in the Netherlands the lower socioeconomic position of the migrant groups partly explained their less favourable health status, but a study among Turkish people indicated that their health status was also lower than that of Dutch people of comparable socioeconomic status. ${ }^{27}$

Time spent watching TV, which can be considered an indirect indicator of (lack of) physical activity, was the other main factor contributing to the difference between overweight prevalence of German and other children. Physical inactivity is a risk factor for obesity in children. ${ }^{31}{ }^{32}$ Time spent with television viewing has been associated with body fatness in children of various ethnicities in some, ${ }^{33-35}$ but not all studies. ${ }^{36}$ Although time spent with television viewing is related to indicators of low socioeconomic status, such as low maternal education and low family income, ${ }^{37}$ it further contributed to explain ethnic differences in overweight in our study even after consideration of maternal education.

One limitation of our study is that, as in other studies comparing children from various nationalities, anthropometric data from migrant children were compared to reference data for German children, based on pooled data of 17 studies conducted in various regions of Germany. No reference data for children with other nationality living in Germany are available yet, nor were reference data for Turkish children (the biggest group of children with other than German nationality in our study population) from Turkey published in the literature. However, when using international reference values for overweight in children, ${ }^{18}$ the differences in prevalence of overweight between children of the considered nationalities essentially stayed the same, even though the absolute prevalence was higher in all subgroups. Another intriguing question that could not be assessed with adequate power in this study, despite its large size, was that of potential interactions between nationality

Table 4 Contribution of suggested risk factors to differences in prevalence of overweight (according to German reference values) by nationality

\begin{tabular}{llll}
\hline Included variables into the regression model & $\mathbf{n}$ & OR* $^{*}$ & $\mathbf{9 5 \%} \mathbf{C l}$ \\
\hline Crude OR for other nationality & 1974 & 2.23 & 1.62 to 3.09 \\
OR for other nationality after adjustment for education of mother & 1974 & 1.52 & 1.06 to 2.17 \\
After additional adjustment for watching TV on weekdays & 1965 & 1.37 & 0.95 to 1.99 \\
After full adjustment† & 1920 & 1.30 & 0.87 to 1.93 \\
\hline
\end{tabular}

*Reference category: German nationality.

†Adjustment for education of mother and education of father, watching TV on weekdays and watching TV on weekends, doing sports or playing outside, consumption of sweets, consumption of savoury snacks, consumption of soft drinks, visiting fast-food restaurants, BMI of mother, and BMI of father. 
What is already known on this topic

- Prevalences of overweight differ by ethnic groups

\section{What this study adds}

- Determinants responsible for prevalence differences are non-ethnic but socioeconomic factors

and lifestyle covariates - that is, potential variations in the role of lifestyle factors between nationalities. Such interactions, which might be of clear relevance for public health measures, should be specifically addressed in future, even larger studies.

In conclusion, our results clearly indicate that prevalence of overweight among children varies greatly between children of different nationalities and countries of origin living in the same country. These apparent ethnic differences can be explained by two non-ethnic but socioeconomic factors. Therefore, in order to prevent overweight in children, it is important to identify and deal with high risk environments rather than high risk ethnic groups. There is the need to change mothers' beliefs about diet, or about fat children being healthy children, and to inform especially low educated mothers about healthy lifestyle. Furthermore, there is the need to understand why children watch television a lot and to offer alternatives to TV as a form of low cost childcare. Due to the early onset of obesity at the age of 6 , prevention efforts should start prior to school entrance. In Germany every child is offered nine routine paediatric check-ups between birth and the age of 6 . These check-ups, which are attended by many children and their parents, might provide an excellent opportunity for paediatricians to address the weight development of the child and to consult the parents regarding prevention of overweight among their children.

\section{ACKNOWLEDGEMENTS}

We would like to thank the staff of the Aachen Public Health Service, Sandra Schaefer, Christine Schell, Martina Selzner, and Christine Wehle for their support and cooperation in field work of this study.

\section{Authors' affiliations}

J Kuepper-Nybelen, $\mathrm{H}$ Brenner, Department of Epidemiology, German Centre for Research on Ageing, Heidelberg, Germany

A Lamerz, N Bruning, B Herpertz-Dahlmann, Department of Child and Adolescent Psychiatry, Technical University of Aachen, Germany J Hebebrand, Clinical Research Group, Department of Child and Adolescent Psychiatry, Philipps University of Marburg, Germany

Funding: This study was funded by the German Society for the Advancement of Scientific Research (DFG grants HE 1809/5-1 and BR 1704/4-1) and by the START-Program of the Medical Faculty, RWTH Aachen, Germany

Competing interests: none declared

\section{REFERENCES}

1 Popkin BM, Doak CM. The obesity epidemic is a worldwide phenomenon. Nutr Rev 1998;56:106-14.

2 Wang Y, Monteiro C, Popkin BM. Trends of obesity and underweight in older children and adolescents in the United States, Brazil, China, and Russia. Am J Clin Nutr 2002;75:971-7.

3 Chinn S, Rona RJ. Prevalence and trends in overweight and obesity in three cross sectional studies of British children, 1974-1994. BMJ 2001;322:24-6.
4 Herpertz-Dahlmann B, Geller F, Böhle C, et al. Secular trends in body mass index measurements in preschool children from the city of Aachen, Germany. Eur J Pediatr 2003;162:104-9.

5 Charney E, Goodman HC, MacBride M, et al. Childhood antecedents of adult obesity: do chubby infants become obese adults? N Engl J Med 1976;295:6-9

6 Stark O, Atkins E, Wolff OH, et al. Longitudinal study of obesity in the National Survey of Health and Development. BMJ 1981;283:13-17.

7 Must A, Jacques PF, Dallal GE, et al. Long-term morbidity and mortality of overweight adolescents: a follow-up of the Harvard Growth Study of 1922 to 1935. N Engl J Med 1992;327:1350-5

8 Power C, Lake JK, Cole TJ. Measurement and long-term health risks of child and adolescent fatness. Int J Obes Relat Metab Disord 1997:21:507-26.

9 Rosner B, Prineas R, Loggie J, et al. Percentiles for body mass index in US children 5 to 17 years of age. J Pediatr 1998;132:211-22.

10 Ogden CL, Troiano RP, Briefel RR, et al. Prevalence of overweight among preschool children in the United States 1971 through 1994. Pediatrics 1997;99:el.

11 Lobstein T, Frelut ML. Prevalence of overweight among children in Europe. Obes Rev 2003;4:195-200.

12 Wang Y. Cross-national comparison of childhood obesity: the epidemic and the relationship between obesity and socioeconomic status. Int J Epidemiol 2001;30:1129-36.

13 Patterson ML, Stern S, Crawford PB, et al. Sociodemographic factors and obesity in preadolescent black and white girls: NHLBI's growth and health study. J Natl Med Assoc 1997;89:594-600.

14 Gordon-Larson P, Adair LS, Popkin BM. Ethnic differences in physical activity and inactivity patterns and overweight status. Obes Res 2002;10:141-9.

15 Crawford PB, Obarzanek E, Schreiber GB, et al. The effect of race, household income, and parental education on nutrient intake of 9-and 10-year-old girls. $\mathrm{NHLBI}$ growth and health study. Ann Epidemiol 1995;5:360-8.

16 Coon KA, Goldberg J, Rogers BL, et al. Relationships between use of television during meals and children's food consumption patterns. Pediatrics 2001; 107:e7

17 Kromeyer-Hauschild K, Wabitsch M, Kunze D, et al. Body mass index percentiles for children and adolescents with consideration of various German samples [in German]. Monatsschr Kinderheilkd 2001;149:807-18.

18 Cole TJ, Bellizzi MC, Flegal KM, et al. Establishing a standard definition for child overweight and obesity worldwide: international survey. BMJ 2000;320:1240-3

19 Statistical yearbook 2002 for the Federal Republic of Germany. Wiesbaden: Federal Statistical Office, 2002.

20 Statistical yearbook of the city of Aachen 2001. Aachen: Statistical Office of the city of Aachen, 2001.

21 Bronner YL. Nutritional status outcomes for children: ethnic, cultural, and environmental contexts. J Am Diet Assoc 1996;96:891-903.

22 Park MK, Menard SW, Schoolfield J. Prevalence of overweight in a triethnic pediatric population of San Antonio, Texas. Int J Obes Relat Metab Disord 2001;25:409-16.

23 Rona RJ, Chinn S. National study of health and growth: social and biological factors associated with weight-for-height and triceps skinfold of children from ethnic groups in England. Ann Hum Biol 1987;14:231-48.

24 Chinn S, Hughes JM, Rona RJ. Trends in growth and obesity in ethnic groups in Britain. Arch Dis Child 1998;78:513-17.

25 Saxena S, Ambler G, Cole TJ, et al. Ethnic group differences in overweight and obese children and young people in England: cross sectional survey. Arch Dis Child 2004;89:30-6.

26 Roville-Sausse F. Increase during the last 20 years of body mass of children 0 to 4 years of age born to Maghrebian immigrants [in French]. Rev Epidemiol Sante Publique 1999:47:37-44.

27 Brussaard JH, van Erp-Baart MA, Brants HA, et al. Nutrition and health among migrants in the Netherlands. Public Health Nutr 2001;4:659-64.

28 Kalies H, Lenz J, von Kries R. Prevalence of overweight and obesity and trends in body mass index in German pre-school children, 1982-1997. Int J Obes 2002; 26:1211-17.

29 Sobal J, Stunkard AJ. Socioeconomic status and obesity: a review of the literature. Psychol Bull 1989;105:260-75.

30 Parsons TJ, Power C, Logan S, et al. Childhood predictors of adult obesity: a systematic review. Int J Obes Relat Metab Disord 1999;23(suppl 8):S1-107.

31 Dietz WH, Gortmaker SL. Do we fatten our children at the television set? Obesity and television viewing in children and adolescents. Pediatrics 1985;75:807-12.

32 Andersen RE, Crespo CJ, Bartlett SJ, et al. Relationship of physical activity and television watching with body weight and level of fatness among children. JAMA 1998;279:938-42

33 Gortmaker SL, Must A, Sobol AM, et al. Television viewing as a cause of increasing obesity among children in the United States, 1986-1990. Arch Pediatr Adolesc Med 1996;150:356-62.

34 Hernandez B, Gortmaker SL, Colditz GA, et al. Association of obesity with physical activity, television programs and other forms of video viewing among children in Mexico City. Int J Obes Relat Metab Disord 1999;23:845-54.

35 Tanasescu M, Ferris AM, Himmelgreen DA, et al. Biobehavioral factors are associated with obesity in Puerto Rican children. J Nutr 2000;130:1734-42.

36 Robinson TN, Hammer LD, Killen JD, et al. Does television viewing increase obesity and reduce physical activity? Cross-sectional and longitudinal analyses among adolescent girls. Pediatrics 1993;91:273-80.

37 Gordon-Larson P, McMurray RG, Popkin BM. Determinants of adolescent physical activity and inactivity patterns. Pediatrics 2000;105:e83. 